\section{JURNAL ABDIMAS

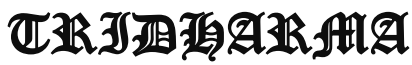 AfA}

\title{
PENGENALAN UANG ELEKTRONIK UNTUK MOBILITAS \\ DAN KEAMANAN TRANSAKSI
}

\author{
Evita Vibriana, Setyanto, Endang Nurita, Ninik Anggraeni, Ahmad Akbar
}

Dosen Ekonomi Fakultas Ekonomi Akutansi Universitas Pamulang

Email dosen01602@unpam.ac.id, dosen01600@unpam.ac.id, dosen01972@unpam.ac.id, dosen00976@unpam.ac.id, dosen01973@unpam.ac.id.

\begin{abstract}
ABSTRAK
Pesatnya perkembangan teknologi dan informasi juga menciptakan kemajuan dibidang perekonomian khususnya sistem pembayaran. Semakin meluasnya penggunaan internet menuntut keseluruhan sistem agar dapat bekerja secara efektif dan praktis yang akhirnya memunculkan inovasi dalam bidang instrument pembayaran yang diciptakan untuk menggantikan alat pembayaran berupa uang tunai.

Kecenderungan pembayaran non tunai dalam hal ini pemakaian alat pembayaran kartu kredit dan uang elektronik(e-money),dari tahun ketahun semakin mengalami kenaikan. Hal itu merupakan issu menarik yang akan penuli sangkat sebagai topic dalam penelitianini, yaitu tentang analisa perbandingan jumlah transaksi dengan menggunakan uang elektronik(emoney)dan menggunakan kartu kredit studi kasus bank Bumn (periode 2010 sampai dengan 2015)

Berdasarkan Undang-undang Nomor 23 Tahun 1999 yang diubah menjadi Undangundang Nomor 3 Tahun 2004, mengamanatkan bahwa salah satu tujuan Bank Indonesia adalah mencapai dan memelihara kestabilan nilai rupiah. Untuk mencapai tujuan tersebut Bank Indonesia didukung oleh tiga pilar yang merupakan tiga bidang tugasnya salah satunya mengatur dan menjaga kelancaran system pembayaran. Dengan demikian, Bank Indonesia memang memiliki tanggung jawab agar masyarakat luas dapat memperoleh jasa system pembayaran yang efisien, cepat, tepat, dan aman.(Arifin Susanto, 2009:127).

Dalam kegiatan PKM Pelatihan Tentang Pengenalan Uang Elektronik Untuk Mobilitas Dan Keamanan Transaksi, dimana dalam pelatihan ini memberi wawasan dan pengetahuan kepada generasi muda adanya perkembangan tehnologi yang cukup pesat tentang uang elektronik. Lembaga pendidikan diharapkan juga mampu memberikan pengarahan, khususnya para Santri. Beberapa langkah yang ditempuh sebagai metode untuk melaksanakan solusi terhadap permasalahan yang dihadapi yayasan akan dilakukan dengan beberapa hal berikut ini: 1.Sosialisasi Program 2.Koordinasi 3.Pelaksanaan Program 4.Evaluasi Program.

Hasil dari pengabdian kepada masyarakat ini adalah supaya para Santri dan Santriawan di Yayasan Alkamilah berubah pola pikirnya. Pelatihan dilakukan dengan game-game yang menarik untuk menguji kemampuan dan wawasan peserta.
\end{abstract}

Kata-kata Kunci : Uang Elektronik, Mobilitas, Keamanan Transaksi, 


\section{JURNAL ABDIMAS

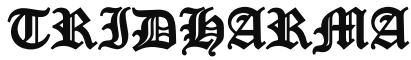

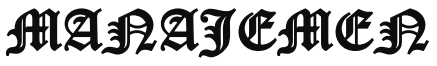

P-ISSN 2615-6849, E-ISSN 2716-070X

Jurnal ABDIMAS Vol.3,No.1,Desember 2021,Hal(38-49)

@ Prodi Manajemen Fakultas Ekonomi Universitas Pamulang

Email: abdimasjurnal.unpam@gmail.com Telp: (021) 741-2566

\begin{abstract}
The rapid development of technology and information has also created progress in the economy, especially the payment system. The increasingly widespread use of the internet requires the entire system to work effectively and practically which eventually led to innovations in the field of payment instruments that were created to replace the payment instrument in the form of cash.

The trend of non-cash payments, in this case the use of credit card payment instruments and electronic money (e-money), is increasing from year to year. This is an interesting issue that the writer will discuss as a topic in this research, namely the comparative analysis of the number of transactions using electronic money (e-money) and using a credit card case study of the StateOwned Enterprises (2010 to 2015 period).

Based on Act Number 23 of 1999 which was amended to Act Number 3 of 2004, it is mandated that one of the objectives of Bank Indonesia is to achieve and maintain stability in the value of the rupiah. To achieve this goal, Bank Indonesia is supported by three pillars, which are three areas of its duties, one of which is to regulate and maintain the smooth running of the payment system. Thus, Bank Indonesia does have a responsibility so that the wider community can obtain payment system services that are efficient, fast, precise, and safe. (Arifin Susanto, 2009:127).

In the PKM activity, the training on the introduction of electronic money for mobility and transaction security, in which this training provides insight and knowledge to the younger generation of the rapid development of technology about electronic money. Educational institutions are also expected to be able to provide direction, especially the students. Some of the steps taken as a method to implement solutions to problems faced by the foundation will be carried out with the following things: 1. Program socialization 2. Coordination 3. Program implementation 4. Program evaluation.

The result of this community service is that the Santri and Santriawan at the Alkamilah Foundation change their mindset. The training is carried out with interesting games to test the abilities and insights of the participants.
\end{abstract}

Keywords: Electronic Money, Mobility, Transaction Security,

\section{PENDAHULUAN}

Pada sistem pembayaran pertama kali menggunakan sistem barter yaitu pertukaran suatu barang atau komoditi dengan komoditi lain secara langsung sesuai dengan kebutuhan yang bersangkutan. Tetapi sistem ini mempunyai keterbatasan-keterbatasan seperti tidak efisien dan tidak adanya kesepakatan standar rmengenai nilai suatu barang. Dengan adanya keterbatasanketerbatasan tersebut dan semakin berkembangnya perekonomian maka diperlukanlah suatu benda (yang disebut uang) yang dapat digunakan sebagai alat tukar tetapi mempunyai nilai tetap dan dapat diterim masyarakat luas.(Burhanuddin Abdullah, 2006: 09)

Uang merupakan alat yang akhirnya menjadi alat tukar mempunyai sejarah

yang panjang. Bentuk uang pada awalnya merupakan suatu barang yang dapat disukai banyak orang dan jumlahnya pun terbatas. Perkembangan selanjutnya adalah logam dijadikan sebagai uang dalam bentuk, ukuran, dan berat yang berbeda-beda yang disebut juga sebagai uang logam(metalic money). Terbatasnya jumlah logam yang 


\section{JURNAL ABDIMAS

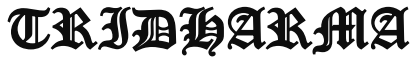

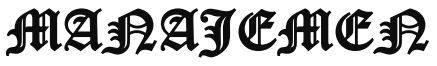

P-ISSN 2615-6849, E-ISSN 2716-070X

Jurnal ABDIMAS Vol.3,No.1,Desember 2021,Hal(38-49)

@ Prodi Manajemen Fakultas Ekonomi Universitas Pamulang

Email: abdimasjurnal.unpam@ gmail.com Telp: (021) 741-2566 dapat digunakan untuk membuat uang, maka muncullah pemikiran untuk menciptakan uang dari bahan kertas.Terciptanya uang kertas tidak langsung melenyapkan uang logam, melainkan uang kertas dan uang logam berdampingan dalam sistem pembayaran.(SitiHidayati, $2006: 01$ )

Sejalan dengan perkembangan perekonomian dari waktu ke waktu, bentuk uang semakin bervariasi. Uang kertas dan uang logam yang juga disebut sebagai uang kartal kemudian dilengkapi dengan uang giral dalam bentuk cek dan giro. Uang kartal dan uang giral dapat juga disebut sebagai uang tunai, yaitu dapat langsung digunakan sebagai mana fungsi uang. (SitiHidayati, 2006 :08)

Pesatnya perkembangan teknologi dan informasi juga menciptakan kemajuan di bidang perekonomian khususnya system pembayaran.Semakin meluasnya penggunaan internet menuntut keseluruhan sistem agar dapat bekerja secara efektif dan praktis yang akhirnya memunculkan inovasi dalam bidang instrument pembayaran yang diciptakan untuk menggantikan alat pembayaran berupa uang tunai.Berdasarkan Undang-undang Nomor 23 Tahun 1999 yang diubah menjadi Undang-undang Nomor 3 Tahun 2004, mengamanatkan bahwa salah satu tujuan Bank Indonesia adalah mencapai dan memelihara kestabilan nilai rupaih. Untuk mencapai tujuan tersebut Bank Indonesia didukung oleh

tiga pilar yang merupakan tiga bidang tugasnya salah satunya mengatur dan menjaga kelancaran system pembayaran.Dengan demikian, Bank Indonesia memang memiliki tanggung jawab agar masyarakat luas dapat memperoleh jasa system pembayaran yang efisien, cepat, tepat, danaman.(ArifinSusanto, 2009:127)

Aktivitas masyarakat pada umumnya dan pebisnis khususnya menuntut adanya efektif kerja dan efisiensi waktu dari setiap transaksi yang dilakukannya. Hal ini lah yang mendorong fasilitas-fasilitas yang ditawarkan oleh banyak instansi terkait dengan transaksi tersebut. Disamping memberikan berbagai kemudahan dalam bertransaksi, pengguna analat pembayaran nontunai secara luas diduga memiliki implikasi pada berkurangnya permintaan terhadap uang yang diterbitkan bank sentral, yaitu base money, yang pada gilirannya dapat mempengaruhi pelaksanaan tugas bank sentral dalam melaksanakan kebijakan moneter, khususnya dalam pengendalian besaran moneter(CostadanGrauwe,2001).

$\begin{array}{rr}\text { Perkembangan } & \text { transaksi } \\ \text { pembayaran menuju cash-less society }\end{array}$ merupakan arah perubahan yang tidak dapat dihindari. Dengan keuntungan yang diperoleh Negara melalui penghematan biaya transaksi, diharapkan adanya kecenderungan arah perubahan transaksi tunai menuju transaksi non tunai. Kartu kredit, kartu debit, dan kartu ATM adalah bentuk kartu pembayaran elektronik yang memfasilitasi pembayaran non tunai dan mempermudah masyarakat menyelesaikan proses transaksi. Perkembangan jumlah dan nilai transaksi non tunai tercatat pada laporan bank dan lembaga penyelenggara selain bank.

Sementara itu, nilai transaksi tunai yang aktual terjadi sulit diukur.

Berkembangnya alat pembayaran menggunakan kartu akan mengurangi transak situnai (cash transaction) dan diharapkan menciptakan efisiensi, mengingat pengelolaan uang tunai sangat mahal dan bagi bank sentral itu adalah biaya terbesar kedua setelah biaya sumber daya manusia (SDM). Sedangkan bagi masyarakat, transaksi non tunai(non cash transaction)akan lebih mudah, cepat, praktis, dan mengurangi risiko kejahatan. (Nirmala, 2011).

Kecenderungan pembayaran non tunai dalam hal ini pemakaian alat pembayaran kartu kredit dan uang elektronik(e-money),dari tahun ketahun 


\section{JURNAL ABDIMAS

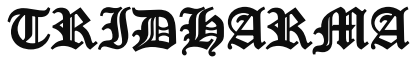

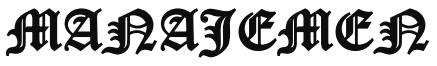

P-ISSN 2615-6849, E-ISSN 2716-070X

Jurnal ABDIMAS Vol.3,No.1,Desember 2021,Hal(38-49)

@ Prodi Manajemen Fakultas Ekonomi Universitas Pamulang

Email: abdimasjurnal.unpam@ gmail.com Telp: (021) 741-2566 semakin mengalami kenaikan. Hal itu merupakan issu menarik yang akan penuli sangkat sebagai topic dalam penelitianini, yaitu tentang analisa perbandingan jumlah transaksi dengan menggunakan uang elektronik(e-money)dan menggunakan kartu kredit studi kasus bank Bumn (periode 2010 sampai dengan 2015)

Dalam program kegiatan Pengabdian Kepada Masyarakat (PKM) kali ini sasaran kami adalah santriawan santriwati asuhan Yayasan Alkamilah Sawangan Depok Jawa Barat. Yayasan Alkamilah adalah tempat untuk mendidik para santriwan santriwati, dimana saat ini menampung para santriwan santriwatinya berasal dari kaum dhuafa dan miskin untuk belajar di Yayasan ini, dimana memberikan tambahan ilmu pengetahuan melalui kegiatan Pengabdian Masyarakat (PKM), dalam hal ini melalui pemberian materi pada Santriwan Santriwati untuk bekal dikehidupannya kelak., sebagai wujud Tri Darma Perguruan Tinggi, Fakultas Ekonomi S1 UNPAM, maka akan menyelenggarakan Pengabdian Kepada Masyarakat (PKM) dengan judul ":Pengenalan Uang Elektronik Untuk Mobilitas Dan Keamanan Transaksi.

\section{TINJAUAN PUSTAKA}

\section{Pengertian Uang Elektronik}

Pengertian Uang Elektronik, Bank for International Settlement (BIS) dalam salah satu publikasinya pada bulan Oktober 1996 mendefinisikan uang elektronik sebagai stored-value or prepaid products in which a record of the funds or value available to a consumer is stored on an electronic device in the consumer's possession.(Basel,1996:01)

Uang elektronik yang dimaksud adalah alat pembayaran elektronik yang diperoleh dengan menyetorkan terlebih dahulu sejumlah uang kepada penerbit, baik secara langsung, maupun melalui agen-agen penerbit atau dengan pendebitan rekening di bank, dan nilai uang tersebut dimasukan menjadi nilai uang dalam media uang elektronik, yang dinyatakan dalam satuan rupiah, yang digunakan untuk melakukan transaksi pembayaran dengan cara mengurangi secara langsung nilai uang pada media uang elektronik tersebut.(Veithal Rivai,2001:136)

Fungsi Uang Elektronik, Dalam perekonomian modern lalu lintas pertukaran barang dan jasa sudah sedemikian cepatnya sehingga memerlukan dukungan tersedianya sistim pembayaran yang handal yang memungkinkan dilakukannya pembayaran secara lebih cepat, efisien, dan aman.Penggunaan uang cash sebagai alat pembayaran dirasakan mulai menimbulkan masalah, terutama

tingginya biaya cash handling dan rendahnya velocity of money. (Siti Hidayati,2006:02)

Sistim pembayaran mikro mengalami perkembangan cukup pesat di berbagai negara dewasa ini, seiring dengan perkembangan teknologi dan kebutuhan masyarakat untuk menggunakan alat pembayaran yang mudah, aman dan efisien.Instrumen pembayaran mikro adalah instrumen pembayaran yang didesain untuk menangani kebutuhan transaksi dengan nilai yang kecil namun dengan volume yang tinggi serta membutuhkan waktu pemrosesan transaksi yang relatif lebih cepat.(BI,2006:04)

Kebutuhan instrumen pembayaran mikro timbul karena apabila pembayaran dilakukan menggunakan instrumen pembayaran lain yang ada saat ini, misalnya uang tunai, kartu debit, kartu kredit dan sebagainya menjadi relatif tidak praktis dan efisien. Uang elektronik muncul sebagai jawaban atas kebutuhan terhadap instrumen pembayaran mikro yang diharapkan mampu melakukan proses pembayaran secara cepat dengan biaya yang relatif murah karena pada umumnya nilai uang yang disimpan instrumen ini ditempatkan pada suatu tempat tertentu yang mampu diakses cepat secara off-line, aman dan murah. (Siti Hidayati,2006:08) 


\section{JURNAL ABDIMAS

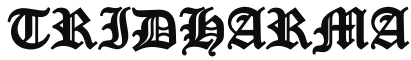

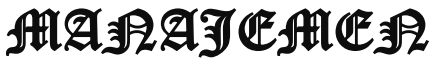

\section{Bentuk-bentuk Uang Elektronik}

\section{Berdasarkan Medianya}

Uang elektronik memiliki media elektronik yang berfungsi sebagai penyimpan nilai uang (monetary value) yang dibedakan atas dua jenis :

a.) Uang elektronik yang nilai uang elektroniknya selain dicatat pada media elektronik yang dikelola oleh penerbit juga dicatat pada media elektronik yang dikelola oleh pemegang. Media elektronik yang dikelola oleh pemegang dapat berupa cardbased dalam bentuk chip yang tersimpan pada kartu atau berupa software-based yang tersimpan pada harddisk yang terdapat pada personal computer milik pemegang. Dengan sistem pencatatan seperti ini, maka transaksi pembayaran dengan menggunakan uang elektronik dapat dilakukan secara off-line dengan mengurangi secara langsung nilai uang elektronik pada media elektronik yang dikelola oleh pemegang (Siti Hidayati,2006:07)

b.) Uang elektronik yang nilai uang elektroniknya hanya dicatat pada media elektronik yang dikelola oleh penerbit. Dalam hal ini pemegang diberi hak akses oleh penerbit terhadap penggunaan nilai uang elektronik tersebut. Dengan sistem pencatatan seperti ini, maka transaksi pembayaran dengan menggunakan uang elektronik ini hanya dapat dilakukan secara on-line dimana nilai uang elektronik yang tercatat pada media elektronik yang dikelola penerbit akan berkurang secara langsung. (BI,2009:02)

\section{Berdasarkan Masa Berlaku Media Uang Elektronik}

Berdasarkan masa berlaku medianya, uang elektronik dibedakan kedalam dua bentuk :

\section{a).Realoadable}

Uang elektronik dengan bentuk reloadable adalah uang elektron yang dapat di lakukan pengisian ulang, dengan kata lain, apabila masa

berlakunya sudah habis dan nilai uang elektroniknya sudah habis terpakai, maka media uang elektronik tersebut dapat digunakan kembali untuk di lakukan pengisian ulang;(BI,2009:27)

\section{b.). Disposable}

Uang elektronik dengan bentuk disposable adalah uang elektronik yang tidak dapat diisi ulang, apabila masa berlakunya sudah habis dan nilai uang elektroniknya sudah habis terpakai, maka media uang elektronik tersebut tidak dapat digunakan kembali untuk di lakukan pengisian ulang.(BI,2009:27)

\section{Berdasarkan Jangkauan Penggunaannya.}

Uang elektronik berdasarkan jangkauan penggunaannya dibedakan ke dalam dua bentuk :

Single-purpose adalah uang elektronik yang digunakan untuk melakukan pembayaran atas kewajiban yang timbul dari satu jenis transaksi ekonomi, misalnya uang elektronik yang hanya dapat digunakan untuk pembayaran tol atau uang elektronik yang hanya dapat melakukan pembayaran atas kewajiban yang timbul dari berbagai jenis transaksi ekonomi, misalnya uang elektronik yang dapat digunakan untuk pembayaran tol, telepon, transportasi umum, dan untuk berbelanja.(Veithal Rivai,2001:1368)

\section{Jenis-jenis pada uang elektronik}

Jenis-jenis transaksi dengan menggunakan uang elektronik secara umum meliputi :

a)Penerbitan (Issuance) dan Pengisian Ulang (Top-up atau Loading)

Pengisian nilai uang kedalam media uang elektronik dapat dilakukan terlebih dahulu oleh penerbit sebelum dijual kepada pemegang. Untuk selanjutnya pemegang 


\section{JURNAL ABDIMAS

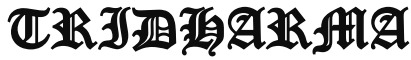

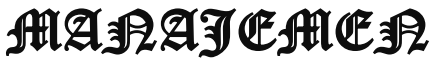

dapat melakukan pengisian ulang (top up) yang dapat dilakukan dengan berbagai cara, antara lain melalui penyetoran uang tunai, melalui pendebitan rekening di bank, atau melalui terminal-terminal pengisian ulang yang telah dilengkapi peralatan khusus oleh penerbit.(Siti Hidayati,2006:10)

\section{b)Transaksi Pembayaran}

Transaksi pembayaran dengan menggunakan uang elektronik pada prinsipnya dilakukan melalui pertukaran nilai uang dalam bentuk data elektronik dengan barang antara pemegang dan pedagang dengan menggunakan protokol yang telah ditetapkan sebelumnya. (Siti Hidayati,2006:11)

\section{- Transfer,}

Transfer dalam transaksi uang elektronik adalah fasilitas pengiriman nilai uang elektronik antar pemegang uang elektronik melalui terminal-terminal yang telah dilengkapi dengan peralatan khusus oleh penerbit. (Siti Hidayati,2006:10)

\section{- Tarik Tunai}

Tarik tunai adalah fasilitas penarikan tunai atas nilai uang elektronik yang tercatat pada media uang elektronik yang dimiliki pemegang yang dapat dilakukan setiap saat oleh pemegang.(Peraturan Bank Indonesia Nomor ,2009)

\section{- Refund/Redeem}

Refund/redeem adalah penukaran kembali nilai uang elektronik kepada penerbit, baik yang dilakukan oleh pemegang pada saat nilai uang elekronik tidak terpakai atau masih tersisa pada saat pemegang mengakhiri penggunaan uang elektronik dan atau masa berlaku media uang elektronik telah berakhir(Peraturan Bank Indonesia

Nomor ,2009), maupun yang dilakukan oleh pedagang pada saat penukaran nilai uang elektronik yang diperoleh pedagang dari pemegang atas transaksi jual beli Barang kepada penerbit (Peraturan Bank Indonesia Nomor 2,2009)
Uang elektronik memiliki karakteristik yang berbeda dengan alat pembayaran menggunakan kartu lainnya seperti credit card, charge card, dan debit card/ATM tersebut di atas. Secara umum perbedaan antara uang elektronik dengan alat pembayaran menggunakan kartu lainnya adalah sebagai berikut:(Siti Hidayati,2006:11)

Alasan mengapa kartu pembayaran lebih aman dibandingkan dengan uang tunai:

\section{Catatan pengeluaran dapat dilacak}

Dengan menggunakan kartu pembayaran, maka seluruh aktivitas pembelian akan tercatat, sehingga kita dapat memantau pengeluaran yang dilakukan baik melalui rekening bank maupun kartu anda. Fitur keamanan ini sangat berguna pada saat kita harus membatalkan transaksi yang tidak sah atau transaksi di mana kita tidak merasa melakukannya.

2. Buang jauh-jauh metode pembayaran yang tidak praktis

Bayangkan bila kita mengeluarkan dompet yang besar dan mencolok, atau meraba-raba tas untuk mencari uang tunai setiap kali melakukan pembelian. Tidak hanya rumit, namun gemerincing suara logam maupun suara uang kertas dapat membuat kita menjadi sasaran pencuri yang barangkali ada di sekitar kita. Sementara itu disisi lain, kartu pembayaran menawarkan cara yang lebih bijaksana dan nyaman untuk membawa uang dalam jumlah yang besar, serta dapat membantu untuk melakukan transaksi secara cepat dan tidak terlalu mencolok.

3. Kartu pembayaran dapat diperoleh kembali, sedangkan uang tunai tidak Dikarenakan sifatnya yang anonim, maka apabila Anda kehilangan uang tunai, maka uang tersebut berarti benar-benar hilang. Sedangkan transaksi kartu pembayaran yang tidak sah di mana Anda tidak merasa melakukannya maka transaksi tersebut dapat dibatalkan dan dihentikan secara cepat bahkan dari jarak jauh. 


\section{JURNAL ABDIMAS

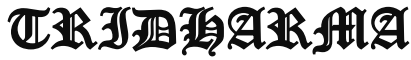

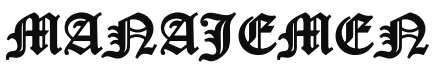

P-ISSN 2615-6849, E-ISSN 2716-070X

Jurnal ABDIMAS Vol.3,No.1,Desember 2021,Hal(38-49)

@ Prodi Manajemen Fakultas Ekonomi Universitas Pamulang

Email: abdimasjurnal.unpam@ gmail.com Telp: (021) 741-2566 4. Keamanan berlapis-lapis dalam kartu
Anda

Berbeda dengan kartu pembayaran, uang tunai tidak memiliki proteksi yang membuatnya relatif mudah untuk dicuri. Kartu pembayaran dilengkapi dengan EMV chip akan memberi otentikasi pembayaran yang lebih menyeluruh, serta menyediakan lapisan keamanan ekstra untuk transaksi pembayaran Anda. Bagaimana mungkin?

Dalam penggunaan kartu pembayaran, telah dibuat sebuah data dinamis yang membuat setiap transaksi dari chip menjadi unik dan secara virtual tidak mungkin untuk ditiru. Kode transaksi unik ini juga dapat digunakan hanya pada saat titik penjualan tertentu, mencegah pencuri untuk menggunakannya kembali untuk transaksi lainnya.

5. Kartu pembayaran menawarkan perlindungan lebih bagi traveler Kartu pembayaran sangat berguna bagi mereka yang sering bepergian. Kartu pembayaran tertentu menawarkan asuransi perjalanan yang mencakup kecelakaan tunggal, kehilangan barang bawaan seperti tas atau koper, maupun penundaan penerbangan. Agar ditanyakan kepada bank penerbit kartu untuk mencari tahu apakah layanan yang mereka tawarkan sudah meliputi asuransi perjalanan. Sehingga kita bisa bepergian dengan tenang dan nyaman karena mengetahui bahwa baik kita maupun kartu sudah terlindungi.

6. Bank memiliki sistem yang dapat melindungi kita pada saat kartu hilang ataupun dicuri Kecelakaan ataupun situasi yang tidak diinginkan tidak bisa dihindari sama sekali. Oleh karena itu, bank memiliki sebuah sistem yang sudah siap untuk meminimalkan kerugian yang terjadi. Apabila merasa kartu Anda hilang atau dicuri, segera beritahu bank sehingga mereka dapat mengambil langkah yang tepat untuk mengamankan uang kita. Pada dasarnya, aspek keamanan dan kenyamanan menjadi faktor pertimbangan utama bagi pelaku transaksi.

\section{Resiko Keamanan}

Uang Elektronik sebagaimana bentuk uang dalam bentuk fisik, memiliki resiko keamanan. Berikut ini adalah faktor resiko keamanan dalam penggunaan Uang Elektronik.

\section{Pencurian}

Bentuk kejahatan E-money yang paling sederhana adalah dengan mencuri Kartu $E$ money milik orang lain untuk kemudian menggunakan dana yang masih tersisa.

Pencurian juga dapat dilakukan oleh oknum penyelenggara E-money, misalnya dengan melakukan pengisian dana secara tidak legal. Pencurian juga bisa dilakukan misalnya dengan cara

mencuri kunci cryptographic tanpa sepengetahuan perusahaan.

\section{Duplication of devices}

Resiko kejahatan ini merupakan upaya untuk membuat duplikasi dari kartu asli, sehingga dapat digunakan untuk melakukan transaksi pembayaran sebagaimana kartu asli. Jenis kejahatan ini cukup rumit dan dilakukan oleh oknum yang memiliki tingkat keahlian teknis tinggi. Karena pelaku harus memiliki berbagai tipe chip serta operating system yang persis sama dengan kartu asli.

\section{Alteration or duplication of data/software}

Resiko ini merupakan Resiko kejahatan melalui upaya perubahan atau modifikasi data atau aplikasi yang ada pada kartu asli, sedemikian rupa sehingga pelaku memperoleh keuntungan finansial. Misalnya menambah dana E-money atau merubah sistem internal aplikasi, sehingga prosedur perhitungannya tidak bekerja sebagaimana mestinya. Bisa juga melalui 'physical attacks' terhadap chip itu sendiri.

\section{Alteration of message}

Resiko ini melalui upaya 


\section{JURNAL ABDIMAS

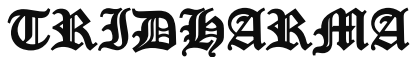 AtA}

P-ISSN 2615-6849, E-ISSN 2716-070X

Jurnal ABDIMAS Vol.3,No.1,Desember 2021,Hal(38-49)

@ Prodi Manajemen Fakultas Ekonomi Universitas Pamulang

Email: abdimasjurnal.unpam@ gmail.com Telp: (021) 741-2566 elektronis/message dikirim, pada saat transaksi berlangsung. Potensi resiko ini, lebih mungkin terjadi ketika E-money digunakan untuk pembayaran melalui internet.

\section{Penyangkalan transaksi (repudiation)}

Penyalahgunaan lainnya dalam penyelenggaraan E-money adalah penyangkalan transaksi. Potensi resiko adalah pada E-money berbasis software dan menggunakan pengiriman message saat transaksi melalui jaringan internet.

\section{Malfunction}

Resiko malfunction dapat berupa data corrupt atau hilang, tidak berfungsinya aplikasi atau kegagalan dalam pengiriman message. Resiko malfunction ini dapat diakibatkan oleh gangguan fisikal maupun elektronis pada instrumen atau karena adanya interupsi saat pengiriman message antara para pihak yang bertransaksi.

Bilamana tingkat keamanan dan kenyamanan telah dinikmati banyak kalangan, berbagai bentuk jual beli eceran, kelak akan menggunakan Kartu Pintar sebagai media pembayaran.

sebagai konsumen yang cerdas kita perlu memperhatikan berbagai aspek dalam bertransaksi menggunakan uang elektronik. Berikut 3 (tiga) hal yang harus diperhatikan sebelum melakukan transaksi uang elektronik:

\section{Keamanan}

Keamanan menjadi hal yang utama dalam bertransaksi, termasuk pembayaran menggunakan uang elektronik. Untuk penggunaan uang elektronik card based, hindari pemindahtanganan kartu. Perlu diingat, transaksi menggunakan uang elektronik card based, tidak menggunakan PIN (Personal Identification Number). Oleh karena itu sebisa mungkin hindari pemindah tanganan kartu saat bertransaksi untuk mengantisipasi penukaran kartu uang elektronik. Bisa juga meminta struk bukti pembayaran untuk menghindari pembebanan biaya dua kali (double deduct). Simpanlah kartu uang elektronikmu dengan baik, karena jika kartu hilang/rusak, berarti anda kehilangan uang sejumlah saldo yang tersimpan dalamnya. Kartu yang hilang juga tidak bisa diurus ataupun diblokir ya.

Sedangkan uang elektronik server based juga mempunyai tantangan keamanannya tersendiri, yaitu cyber crime (kejahatan siber). Untuk menggunakan uang elektronik server based membutuhkan identitas individu pengguna atau kartu pengenal. Pengumpulan data identitas pribadi ini membuka celah kemungkinan terjadinya pencurian atau penyalahgunaan data pribadi, bahkan saldo uang elektronik di dalamnya. Pada perkembangannya penyedia uang elektronik server based saat ini mengembangkan PIN (Personal Identification Number) ataupun OTP (One Time Password) untuk bertransaksi. PIN maupun OTP juga sekaligus dapat melindungi data akun penggunanya, agar tidak mudah diretas. PIN ataupun OTP bersifat personal dan jangan beritahukan kepada siapapun.

\section{Infrastruktur dan Teknologi}

Semua transaksi pembayaran uang elektronik tergantung dengan infrastruktur dan teknologi. Hal ini menyebabkan transaksi menggunakan uang elektronik mempunyai risiko gangguan teknologi seperti server error (down) ataupun mati listrik. Kemungkinan terburuk yang harus diwaspadai adalah batalnya transaksi, tetapi uang atau saldo anda sudah terpotong oleh server. Jika hal ini terjadi, bisa menghubungi merchant terkait (uang elektronik card based), atau pihak penerbit (uang elektronik server based). Selain itu, transaksi pembayaran uang elektronik juga membutuhkan jaringan koneksi internet yang memadai. Tanpa koneksi internet yang stabil, proses pembayaran-pun tidak bisa dilakukan. Tidak hanya itu, khusus untuk uang elektronik server based, konsumen harus mempunyai smartphone yang compatible untuk melakukan pembayaran digital. Termasuk kebutuhan kamera pada HP untuk pembayaran menggunakan uang 


\section{JURNAL ABDIMAS

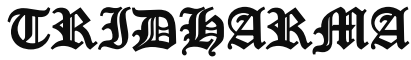

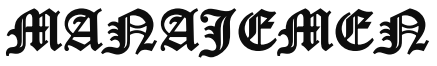

elektronik dengan metode QR Code. Ingat ya, untuk scan kode QRIS.

\section{Buat budget penggunaan uang elektronik}

Dilihat dari pola pemakaiannya, uang elektronik card based biasanya lebih banyak dipakai untuk pembayaran transportasi (tol, KRL, MRT, BRT, LRT) dan parkir kendaraan. Penggunaan uang elektronik card based untuk kebutuhan transportasi biasanya lebih mudah diukur, sehingga tidak terlalu sulit membuat perkiraan budgetnya.

Beda hal dengan transaksi nontunai uang elektronik server based, yang biasanya cenderung membuat konsumen lebih konsumtif. Hal ini disebabkan karena, konsumen merasa tidak mengeluarkan uang sepeser pun saat transaksi (padahal uangnya sudah diubah dalam bentuk saldo), konsumen semakin mudah mendapatkan akses untuk berbelanja (makin banyak merchant yang menerima pembayaran uang elektronik server based), dan promo cashback. Promo diskon atau potongan harga (cashback) saat berbelanja menggunakan uang elektronik mendorong konsumen membeli berbagai macam produk dan jasa karena merasa pembelian atau belanjaan mereka menjadi lebih murah.

Perkembangan teknologi dalam bentuk uang elektronik memang tak bisa dibendung lagi. Kitalah sebagai manusia yang harus pandaipandai menata dan mengatur diri. Membuat budget pengeluaran untuk uang elektronik menjadi penting. Selain berdisiplin anggaran, mengatur budget pengeluaran uang elektronik juga dapat menghindarkan kita dari kecenderungan untuk boros saat bertransaksi non tunai.

Yayasan Alkamilah yang berdiri sejak 30 Oktober 2012 sudah bisa menampung 30 anak asuh di asrama. Sedangkan untuk keseluruhan yang berada di luar mencapai 50 anak. Sehingga, total yang diasuh yayasannya mencapai 80 anak dari Jabodetabek, maupun diluar Jabotabek seperti Kebumen, Purwakarta, Banten dan lainnya. Mereka berasal dari kalangan tidak mampu, dapat masuk ke Yayasan ini. Out put-nya mereka bisa mandiri, baik dirinya pribadi, keluarga dan masyarakat. Kami juga mengadakan kegiatan sosial dalam bentuk santunan ke jompo dan lansia di sekitar yayasan, berkunjung ke rumah-rumah warga tidak mampu. Tapi sifatnya accidental. Setahun kami bisa 4 (Empat) kali santunan. Juga ada pengobatan gratis dan sunatan massal," papar bapak empat orang anak ini. Untuk aspek pengembangan dan inovasi program, Yayasan AlKamilah ingin maju tanpa ketergantungan dengan donatur. Sehingga, setiap ada bantuan dari para pendiri dan donatur, yayasan tersebut menyisihkan untuk membentuk usaha yang menghasilkan. Dengan memperhatikan latar belakang yang telah dipaparkan diatas kami akan mengadakan pengabdian kepada masyarakat tepatnya di lokasi Jl. Serua Raya No.3, Serua, Kec. Bojongsari, Depok, Jawa Barat.

\section{METODE PELAKSANAAN}

Melihat permasalahan yang dihadapi maka langkah-langkah yang dilakukan untuk mencapai tujuan dan sasaran kegiatan ini maka diadakan pendekatan kepada Santriwan dan Santriwati terkait yaitu Santriwan Santriwati di yayasan Alkamilah melalui workshop dan sosialisasi serta pelatihan berupa penjelasan tujuan Penyuluhan Tentang Uang Elektronik untuk santriwan santriwati di yayasan Alkamilah.

Pengabdian Kepada Masyarakat (PKM) akan dilaksanakan Di Yayasan Alkamilah , Kecamatan Sawangan, Kab. Depok, Propinsi Jawa Barat pada bulan Juni 2021. Pembuatan ini akan dibimbing oleh tim pelaksana staf-staf pengajar dari Universitas Pamulang dengan mengikut sertakan peran instansi Yayasan terkait baik Ketua yayasan maupun Santriwan dan Santriwati di yayasan Alkamilah.

\section{Metode Pelatihan}

Metode pelatihan yang diterapkan berdasarkan solusi atas permasalahan Santriwan Santriwati di Yayasan Alkamilah sawangan Depiok. Pengabdian Kepada 


\section{JURNAL ABDIMAS

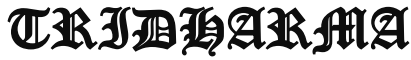

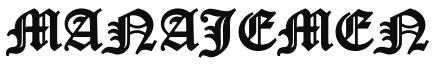

Masyarakat (PKM) akan dilaksanakan di Kecamatan Sawangan, Kab. Depok Propinsi Jawa Barat pada bulan Juni 2021, sebagai berikut :

Hari ke 1: Pengumpulan data (dengan memberikan data wawancara kepada Santriwan santriwati keluhan dan kelemahan tentang uang elektronik)

Hari ke 2: Penyuluhan Mengenai Uang Elektronik kepada Santriwan santriwati di yayasan Al-kamilah.

Hari ke 3: Memberikan Penyuluhan tentang keamanan bertransaksi elektronik kepada para santriwan santriwati [dengan memberikan pelatihan kepada Santriwan santriwati di yayasan alkamilah]

Rencana kegiatan yang akan dilakukan untuk kegiatan ini:

a. Tahap persiapan, Persiapan ini difokuskan dengan menyiapkan semua peralatan yang dibutuhkan untuk melaksanan kegiatan ini, studi literatur dan melakukan koordinasi dengan instansi lembaga yayasan terkait serta ketua yayasan khususnya umumnya pada santriwan santriwati untuk melakukan kegiatan penyuluhan tentang uang elektronik pada santriwan santriwati di yayasan al kamilah.

b. Penentuan Lokasi, Pada tahap ini dilakukan kunjungan ke lokasi untuk menentukan tempat (lokasi) pendampingan serta penyuluhan tentang uang elektronik pada santriwan santriwati di yayasan al kamilah sawangan depok.

c. Perancangan implemnetasi dan pengawasan dalam tentang implementasi uang uang elektronik pada santriwan santriwati di yayasan al kamilah sawangan depok. Prosedur Kerja Untuk melaksanakan program PKM ini, prosedur kerjanya sebagai berikut :

1. Tahap Persiapan Tahap persiapan yang dilakukan meliputi : a. Survei awal, Pada tahap ini dilakukan survei lokasi Yayasan Al Kamilah di Desa Serua, Kec. Sawangan, Kab. Depok.

b. Observasi. Setelah survei maka ditentukan pelaksanaan dan sasaran peserta kegiatan

c. Rapat Koordinasi Tim. Pada tahap ini rapat mengenai pembagian tugas, membuat jadwal pelaksanaan, mulai dari persiapan, pelaksanaan,

laporan.

sampai evaluasi dan penyusunan

2.Tahap Pelaksanaan Tahap pelaksanaan yang dilakukan meliputi :

a. Sosialisasi Program. Pada tahap awal pelaksanaan dilakukan sosialisasi program bisnis syariah kepada santriwan dan santriwati yayasan Alkamilah sawangan depok.

b. Pelatihan/Pendampingan. Sesuai dengan langkah selanjutnya adalah memberikan pelatihan/pendampingan berupa pelatihan tentang uang elektronik pada santriwan santriwati di yayasan Alkamilah

\section{Tahap Evaluasi}

Tahap evaluasi merupakan penilaian setelah rangkaian kegiatan dilakukan oleh pelaksana sesuai dengan jadwal yang telah ditentukan. Evaluasi ini bisa berupa perbaikan atau saran untuk pelaksanaan kegiatan lebih baik lagi dan kelanjutan menjadi binaan kampus khususnya pada pemuda pemudi generasi bangsa. Partisipasi Mitra dalam Pelaksanaan Program Partisipasi mitra dalam pelaksanaan program PKM ini sangat kooperatif dengan memberikan ijin kepada tim untuk melaksanakan pengabdian Masyarakat Khususnya pada santriwan santriwati binaan kampus, memberikan keterangan baik berupa informasi atau datadata yang dibutuhkan sampai rencana pelaksanaan berupa kegiatan penyuluhan atau pendampingan nantinya. 


\section{JURNAL ABDIMAS

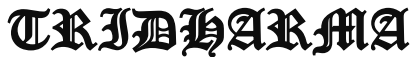

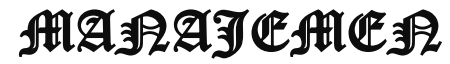

\section{KESIMPULAN DAN SARAN}

\section{Kesimpulan}

Pengabdian Pada Masyarakat Kepada Santriwan Santriwati disebuah yayasan sangat dibutuhkan, dengan memberikan Pelatihan Pengenalan Uang Elektronik Untuk Mobilitas Dan Keamanan Transaksi

Pada Pengabdian Kepada Masyarakat selanjutnya akan diberikan materi-materi pelatihan yang dibutuhkan pasa santriwan santriwati.

Pada Pengabdian Masyarakat selanjutnya melaksanakan pendampingan kepada santriwan santriwati dalam rangka mewujudkan santri yang cerdas dan mengikuti perkembangan tehnologi terutama dalam bidang perbankan. Selain itu juga para dosen Unpam memberikan materimateri pelatihan lainnya yang dibutuhkan.

\section{Saran}

Agar kedepannya nanti kami para dosen Unpam dalam melaksanakan program Pengabdian Kepada Masyarakat bekerjasama dengan yayasan pesantren bisa mewujudkan materi tentang pemberdayaan sumber daya manusia yang berhubungan dengan pembinaan para santri didalam pesantren. Selanjutnya untuk lebih mencerdaskan para santri, perlu juga dibuat perpustakaan dengan mengumpulkan bukubuku bekas yang kami peroleh dari para dosen unpam.

\section{DAFTAR PUSTAKA}

Hidayati, et. al., 2006, Kajian Operasional E-money, Bank Indonesia

Direktorat Akunting dan Sistem Pembayaran Bank Indonesia, 2007, Kebijakan, Implementasi dan Permasalahan APMK di Indonesia, Materi Presentasi dalam Forum Diskusi Penyusunan Kebijakan TI terkait Implementasi APMK.

Pasaribu, V. L. D., Agrasadya, A., Shabrina, N., \& Krisnaldy, K. (2020). Menjadi Enterpreneur Muda Yang Memiliki Jiwa Leadership Untuk Menghadapi Masa Depan. Abdi Laksana: Jurnal
Pengabdian Kepada Masyarakat, 1(1).

Pasaribu, V. L. D., Susanti, F., \& Hartuti, E. T.

K. (2019). Memotivasi Siswa dan Siswi

SMK Letris Indonesia di Dalam

Menentukan Pilihan Untuk

Melanjutkan Pendidikan Atau Bekerja

Setelah Lulus Sekolah. Jurnal

Pengabdian Dharma Laksana, 1(2), 161-172.

Pasaribu, V. L. D., Sulaiman, S., Sutiman, S., Thaharudin, T., \& Purnomo, B. Y. (2020). Pengenalan Letak Posyandu Terdekat Dikelurahan Pisangan Dengan Manajemen Pemasaran Revolusi 4.0 Untuk Meningkatkan Pengetahuan Masyarakat Letak Dan Fungsi Posyandu Terdekat Pada Kelurahan Pisangan. Dedikasi Pkm, l(1), 105-110.

Pasaribu, V. L. D., Oktrima, B., Prabowo, B., Arianto, N., \& Haryoko, U. B. (2020). Progam Pendampingan Dan Penyelenggaraan Pendidikan Anak Pada Usia Dini Terhadap Prestasi Belajar Dilingkungan Rt 020 Rw 009. Kel Giri Peni. Kec Wates. Yogyakarta. Jurnal Lokabmas Kreatif, 1(1), 71-75.

Pasaribu, V. L. D., Jannah, M., Fazar, M., Putra, S. P., Monalisa, M., \& Sofa, M. (2021). MENINGKATKAN PRODUKTIVITAS USAHA DIMASA PANDEMI PADA IBU PKK RT 004/003 KELURAHAN SAWAH BARU CIPUTAT, TANGERANG SELATAN. Abdi Laksana: Jurnal Pengabdian Kepada Masyarakat, 2(2), 295-301.

Pasaribu, V. L. D., Yuniati, H. L., Pranata, R., Sembayu, R., Purba, S. M., \& Nurbayani, T. T. A. (2021). MANAJEMEN KEUANGAN UNTUK MENGHADAPI DAN BERTAHAN DI ERA COVID 19. Jurnal Abdimas Tri Dharma Manajemen, 2(2), 12-18.

Pasaribu, V. L. D., Dwiyatni, A., Sabina, C., Ridwan, M., Gunawan, D. D., \& Noviani, B. C. (2021). EVALUASI PENERAPAN 3M DIMASA PANDEMIC COVID 19. Jurnal Abdimas Tri Dharma Manajemen, 2(2), 54-60.

Pasaribu, V. L. D., Syafei, A. N., Farhan, A., Aufaizah, A., Irani, C., \& Firtiayani, S. R. (2021). PENGARUH DISPLIN PROTOKOL TERHADAP KESEHATAN PENULARAN VIRUS COVID- 


\section{JURNAL ABDIMAS

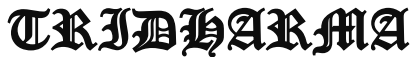

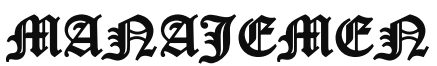

P-ISSN 2615-6849, E-ISSN 2716-070X

Jurnal ABDIMAS Vol.3,No.1,Desember 2021,Hal(38-49)

@ Prodi Manajemen Fakultas Ekonomi Universitas Pamulang

Email: abdimasjurnal.unpam@ gmail.com Telp: (021) 741-2566
19. Jurnal Abdimas Tri Dharma Manajemen, 2(2), 91-98.

Pasaribu, V. L. D., Septiani, F., Rahayu, S., Lismiatun, L., Arief, M., Juanda, A., ... \& Rahim, R. (2021). Forecast Analysis of Gross Regional Domestic Product based on the Linear Regression Algorithm Technique.

Priadi, A., Pasaribu, V. L. D., Virby, S., Sairin, S., \& Wardani, W. G. (2020). Penguatan Ekonomi Kreatif Berbasis Sumber Daya Desa Dikelurahan Rempoa. Abdi Laksana: Jurnal Pengabdian Kepada Masyarakat, 1(3), 356-35

Pasaribu, V. L. D., Priadi, A., Anismadiyah, V., Rahayu, S., \& Maduningtias, L. (2021). PENYULUHAN KREATIF DAN INOVATIF MENINGKATKAN MUTU PRODUKSI UMKM DI DESA BELEGA KABUPATEN GIANYAR. Pro Bono Jurnal Pengabdian Kepada Masyarakat, 1(02).

Pasaribu, V. L. D. (2021). PELATIHAN BERBASIS ONLINE DI ERA COVID-19. Jurnal Abdimas Tri Dharma Manajemen, 2(3), 26-32.

Pasaribu, V. L. D., \& Setyowati, R. (2021). ADAPTASI KEHIDUPAN NEW NORMAL PADA MASA PANDEMI COVID-19 DIYAYASAN PONDOK PESANTREN DAN PANTI ASUHAN NURUL IKHSAN KECAMATAN SETU, KOTA TANGERANG SELATAN. Jurnal Lokabmas Kreatif: Loyalitas Kreatifitas Abdi Masyarakat Kreatif, 2(2), 82-88.

Widyastuti, K., Handayani, P. W., Wilarso, I. (2017). Tantangan dan hambatan implementasi produk uang elektronik di Indonesia: studi kasus
PT XYZ. Journal of Information Systems.

Usman, R. (2017). Karakteristik uang elektronik dalam sistem pembayaran. Journal of law. Vol.32.

Tazkiyyaturrohmah, R. (2018). Eksistensi uang elektronik sebagai alat transaksi keuangan modern. Journal of islamic economy

Ahmad Hidayat, Dkk, Tim Inisiatif 2006 Grand Desain Upaya Peningkatan Penggunaan Pembayaran Non Tunai, 2006,

Upaya Meningkatkan Penggunaan Alat Pembayaran Non Tunai Melalui Pengembangan E-Money, Working Paper, Bank Indonesia, Hal. 1.

Bank for International settelments, Implications for Central Bank of The Development of Electronic Money, (Basel: BIS, 1996), hal. 1

RivaiVeithal, Bank and Financial Institution Management, (Jakarta: PT. Raja GrafindoPersada, 2001), hal. 136

Tim Inisiatif 2006 Bank Indonesia, Working Paper: Upaya Meningkatkan Penggunaan Alat Pembayaran Non Tunai Melalui Pengembangan EMoney, (Jakarta: BI, 2006), hal. 2

SitiHidayati, dkk, Operasional E-Money, (Jakarta: BI, 2006), hal. 7

Penjelasan atas Peraturan Bank Indonesia Nomor 11/12/PBI/2009, tentang Uang elektronik, hal. 2

Surat Edaran Bank Indonesia Nomor 11/11/DASP, Perihal Uang elektronik, (Jakarta: BI, tertanggal 13 April 2009), hal. 27

Rivai Veithal, Bank and Financial Institution Management, (Jakarta: PT. 


\section{JURNAL ABDIMAS

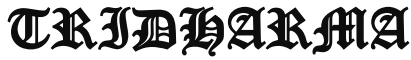 AIA}

P-ISSN 2615-6849, E-ISSN 2716-070X

Jurnal ABDIMAS Vol.3,No.1,Desember 2021,Hal(38-49)

@ Prodi Manajemen Fakultas Ekonomi Universitas Pamulang

Email: abdimasjurnal.unpam@gmail.com Telp: (021) 741-2566

Raja GrafindoPersada, 2001), hal 1367,hal 1368

Siti Hidayati, dkk, Operasional E-Money, (Jakarta: BI, 2006), hal. 10, hal.11, hal. 10
Peraturan Bank Indonesia Nomor 11/12/PBI/2009,
tentangUangelektronik,,Pasal 1ayat 12

Penjelasan atas Peraturan Bank Indonesia Nomor 11/12/PBI/2009,

\section{DOKUMENTASI KEGIATAN}
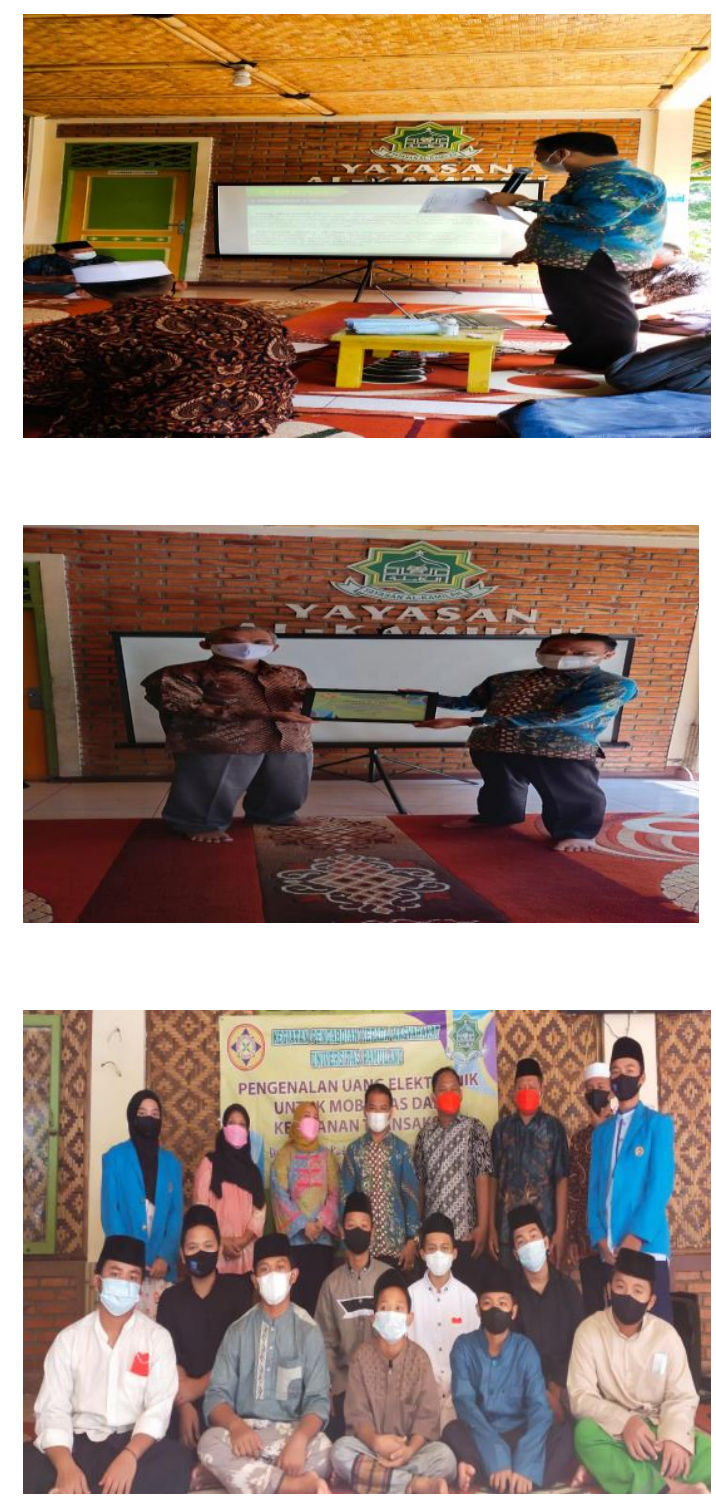